\title{
Introduction
}

\section{Cervical spondylotic myelopathy}

Edward C. Benzel, M.D., ${ }^{1}$ And Zoher Ghogawala, M.D. ${ }^{2}$

${ }^{I}$ Cleveland Clinic, Cleveland, Ohio; and ${ }^{2}$ Lahey Hospital and Medical Center, Burlington, Massachusetts

Cervical spondylotic myelopathy (CSM) is the most common cause of spinal cord dysfunction. ${ }^{7}$ The condition presents insidiously and is defined in terms of its clinical symptoms (gait instability, bladder dysfunction, fine finger motor difficulties) and signs (hyperreflexia, weakness, alteration of joint position sense). Cervical spondylotic myelopathy is caused by dynamic repeated compression of the spinal cord from degenerative arthritis of the cervical spine. ${ }^{2}$ Proposed mechanisms include axonal stretch-associated injury ${ }^{3}$ and spinal cord ischemia from compression of larger vessels and impaired microcirculation., ${ }^{1,2}$ Surgery to decompress and stabilize the spine often is advocated for severe or progressive symptoms, with mixed results. About two-thirds of patients improve with surgery, while surgery is not successful in 15\%-30\% of cases. ${ }^{5}$ Over 112,400 cervical spine operations for degenerative spondylosis are performed annually in the US. This represents a $100 \%$ increase over the previous decade. ${ }^{4}$ Cervical spondylotic myelopathy accounts for nearly $20 \%$ of cervical spine operations in the US, ${ }^{6}$ with annual hospital charges for CSM surgery exceeding 2 billion dollars per year. ${ }^{4}$ In addition, CSM is associated with substantial postsurgical outpatient expenses (for example, physician visits, imaging, physical therapy, medications). Cervical spondylotic myelopathy represents a major health burden in our society and there is a need for more original research to guide our clinical approach to this underdiagnosed condition.

In this issue, we are pleased to include 11 original manuscripts that add to our understanding of CSM in several unique ways. First, we begin with a manuscript that discusses the challenge in diagnosing this clinical entity. We include manuscripts that discuss new insights

Please include this information when citing this paper: DOI: 10.3171/2013.5.FOCUS13211. that are related to imaging, monitoring, epidemiology, and minimally invasive approaches. An evidence-based review on the management of central cord syndrome is also included.

The major debate in the literature over the last 50 years has been the choice of approach: ventral versus dorsal. We include a comparative study on this topic that examines ventral fusion versus laminoplasty and also a comprehensive review of the literature that compares ventral fusion to dorsal fusion for CSM.

Unfortunately, randomized controlled trials for CSM have yet to be performed. Nevertheless, there exists valuable information in the original manuscripts presented here. We hope that each will provide both interest and value to the reader and that the care of patients with CSM will be improved by the information transmitted.

(http://thejns.org/doi/abs/10.3171/2013.5.FOCUS13211)

\section{Disclosure}

The authors report no conflict of interest.

\section{References}

1. al-Mefty O, Harkey HL, Marawi I, Haines DE, Peeler DF, Wilner HI, Smith RR, et al: Experimental chronic compressive cervical myelopathy. J Neurosurg 79:550-561, 1993

2. Baron EM, Young WF: Cervical spondylotic myelopathy: a brief review of its pathophysiology, clinical course, and diagnosis. Neurosurgery 60 (1 Suppl 1):S35-S41, 2007

3. Henderson FC, Geddes JF, Vaccaro AR, Woodard E, Berry KJ, Benzel EC: Stretch-associated injury in cervical spondylotic myelopathy: new concept and review. Neurosurgery 56: 1101-1113, 2005

4. Patil PG, Turner DA, Pietrobon R: National trends in surgical procedures for degenerative cervical spine disease: 19902000. Neurosurgery 57:753-758, 2005

5. Rowland LP: Surgical treatment of cervical spondylotic myelopathy: time for a controlled trial. Neurology 42:5-13, 1992

6. Wang MC, Chan L, Maiman DJ, Kreuter W, Deyo RA: Complications and mortality associated with cervical spine surgery for degenerative disease in the United States. Spine (Phila Pa 1976) 32:342-347, 2007

7. Young WF: Cervical spondylotic myelopathy: a common cause of spinal cord dysfunction in older persons. Am Fam Physician 62:1064-1070, 1073, 2000 (Erratum in Am Fam Physician 63:1916, 2001) 